\title{
Age differences in rereading
}

\author{
ELIZABETH A. L. STINE-MORROW \\ University of Illinois at Urbana-Champaign, Champaign, Illinois \\ DANIELLE D. GAGNE \\ University of New Hampshire, Durham, New Hampshire \\ DANIEL G. MORROW \\ University of Illinois at Urbana-Champaign, Champaign, Illinois \\ and \\ BARBARA HERMAN DEWALL \\ University of New Hampshire, Durham, New Hampshire
}

\begin{abstract}
Younger and older adults read a series of expository and narrative passages twice in order to answer comprehension questions. Reading time was used to index attentional allocation to word, textbase, and situation model processing and to assess shifts in the allocation policy from the first to the second reading. Older readers' comprehension was at least as good as that of younger readers. Analysis of reading times suggested that for both genres, older adults allocated more attention to situation model features than younger adults did on the first reading, whereas young and old allocated attention similarly to this level of representation on the second reading, suggesting that mature readers may give greater priority to situation model construction when first encountering text. Also, for both genres, older adults showed relatively less facilitation than the young in word-level processing in rereading, suggesting that representation at this level is not as firmly established during reading or decays more quickly for older readers. For narrative texts only, this pattern also obtained for textbase processing. Collectively, these data show that age equivalence in text comprehension at the molar level may be accomplished through different processing routes at the molecular level.
\end{abstract}

In the ordinary course of reading, we often reread in order to construct a more complete representation of a text's meaning. Despite the fact that there are several significant demonstrations of age differences in text memory and/or the efficiency with which older adults read for memory and comprehension (e.g., Hartley, Stojack, Mushaney, Annon, \& Lee, 1994; Johnson, 2003; Zelinski \& Gilewski, 1988), little work has systematically investigated the nature or utility of rereading for older adults. In the present article, we report the results of two experiments in which we examined how older and younger adults allocate time to text processing across successive encounters.

\section{What Readers Do When They Reread Text}

In order to fully understand a text, readers decode the surface form to construct both a representation of the

We are grateful for support from the National Institute on Aging (Grant R01 AG13935). We thank Kerrie Griffin and Diane Cad for help with participant testing, scoring, and data entry and Matthew Shake for helpful commentary on the article. Data were collected at the University of New Hampshire. Correspondence concerning this article may be sent to E. A. L. Stine-Morrow, Department of Educational Psychology, University of Illinois at Urbana-Champaign, 226 Education Building MC-708, 1310 South Sixth Street, Champaign, IL 61820 (e-mail: eals@uiuc.edu). content expressed, called the textbase, and a more global representation of what the text is about, called the situation model (Kintsch, 1994, 1998; Kintsch \& van Dijk, 1978). The textbase is conceptualized as an integrated network of idea units (called propositions) that captures the semantic content and conceptual relationships given directly from the text. The situation model, on the other hand, is an elaborated representation in which the propositional content of the text is embellished and integrated with information from the reader's knowledge base. With respect to narratives, the development of the situation model may involve tracking the protagonist as he or she moves in space and time through the narrative world; it may also involve monitoring the goals of the protagonist and determining when those goals have been met, as well as evaluating the protagonist's actions in light of a character profile developed earlier in the story (e.g., Zwaan \& Radvansky, 1998). With respect to expository texts, the situation model may involve tracking lines of arguments (e.g., Britton, 1994; Meyer \& Poon, 2001), gleaning important elements from detail (Millis, Simon, \& tenBroek, 1998), or constructing a working model of how a system functions (Kintsch, 1994). Some researchers (e.g., Kintsch, 1994) have argued that the situation model is necessary for true learning from a text, which enables the reader to use the text to make inferences and to solve 
problems. Thus, we conceptualize the understanding of discourse as requiring collections of computations at three different levels of analysis: the surface form, which includes orthographic decoding and lexical access; the textbase, which includes the propositional and conceptual analysis; and the situation model, which includes spatiotemporal and causal monitoring.

The rereading literature consists of two threads that answer two different sorts of questions. One literature, which might be characterized as the window-into-reading approach, uses facilitation in rereading as a gauge of the representation that was created in the initial encounter with the text (e.g., Levy et al., 1995; Levy, Di Persio, \& Hollingshead, 1992; Levy \& Kirsner, 1989; Levy, Newell, Snyder, \& Timmins, 1986; Raney, 2003; Raney, Therriault, $\&$ Minkoff, 2000). Readers are faster in reprocessing a text, a phenomenon called a text repetition effect, or a rereading benefit. The rereading benefit is attributed to the availability of a memory representation created during reading, which facilitates linguistic computations on subsequent encounters. By manipulating the differences between the texts read on first and second encounters, inferences can be made about the nature of the memory representation constructed on the initial reading: If a change in the text (e.g., typeface, syntactic form, or lexical choice for a concept) diminishes the rereading benefit, that feature is presumed to have been encoded into the memory representation. Thus, in this literature, the rereading benefit is an implicit measure of the content of the memory representation constructed during the initial reading. For example, the finding that, under some conditions, a change in typeface can decrease the rereading benefit (Levy et al., 1992) suggests that the memory representation may contain some output from the perceptual (orthographic) analysis of the text. The finding that a paraphrase reduces the rereading benefit, relative to a verbatim repetition (e.g., Raney et al., 2000), suggests that the memory representation contains some lexical information. The extent to which a repetition benefit is reduced by changes at the lexical or textbase level may depend on the salience of the situation model representation (Raney, 2003).

Another literature, which might be called the rereading gain approach, addresses what is garnered in reprocessing over and above the first encounter with a text. In this approach, exactly the same text is read more than once, as is often done in everyday reading. It is not surprising that among younger readers, rereading can improve subsequent performance in answering comprehension questions (Amlund, Kardash, \& Kulhavy, 1986; Haenggi \& Perfetti, 1992). Haenggi and Perfetti examined the effects of reprocessing on a comprehension task probing the explicit content of the text, implicit information based directly on the text, or implicit information derived from the script. Reprocessing improved performance on explicit questions regardless of ability; however, reprocessing improved average readers' performance on text-implicit questions, whereas it improved above-average readers' performance on script-implicit questions. Thus, they argued that "text reprocessing helped average readers to learn more information that had to be inferred from the text, whereas above-average readers took the reprocessing as an opportunity to combine text information with their prior knowledge" (p. 189).

Interestingly, there is some evidence of a shift in rereading from textbase construction to situation model processing. For example, Millis et al. (1998) asked college students to read and reread a series of scientific texts under instructions for comprehension. In two experiments measuring sentence-by-sentence and word-by-word reading time, regression of reading times onto text characteristics (e.g., Lorch \& Myers, 1990) was used to show that time allocation to proposition assembly decreased across presentations, whereas allocation to discourse-level processing (as measured by the rated importance of the sentence) increased; this finding has been substantively replicated with descriptive texts (Millis, King, \& Kim, 2000). Zwaan, Magliano, and Graesser (1995) have also shown increased attention to situation model processing (as measured by time allocation to spatial discontinuities) when narratives are reread.

A final example from the rereading gain literature is a study by Rawson, Dunlosky, and Thiede (2000), which showed that metacomprehension accuracy improves with rereading. They argued that in monitoring comprehension, readers rely in part on encoding difficulties, or disfluencies, to evaluate their understanding but that the diagnostic value of disfluencies depends on their source. Disfluencies during rereading reflect disruptions of situation model processing, in contrast to disfluencies during initial reading, which reflect disruptions of lexical and textbase processing. Because situation model processing is more important for true comprehension and learning from text, disfluencies on the second reading are actually better predictors of comprehension.

Collectively, these data support a model of discourse processing in which an array of hierarchically arranged processes compete for limited resources (Just \& Carpenter, 1992; Kintsch, 1994). For almost any text of substance, it is virtually impossible to grasp its meaning in an absolute sense (i.e., complete textbase content and full unique understanding of the lines of reasoning or the narrative situation, including the spatiotemporal situation, goal structure, and emotional nuances), but reprocessing enables the reader to build on the representation created in prior encodings with computations not yet conducted. This is enabled in part by the fact that the completion of computations on the first reading frees up resources that do not need to be allocated to these same processes in rereading (resulting in a rereading benefit). At least among young adult readers, the textbase representation appears to have priority over the situation model. Certainly, to some extent, the logic of the system entails this priority, since at least a preliminary understanding of the textbase is necessary as a scaffold for situation model processing. The construction of the textbase on a first 
reading provides a representational grounding for the situation model, while freeing resources for situation model construction on reprocessing. This literature also suggests that there may be individual differences in what readers accomplish in rereading.

\section{Age Differences in Reading}

Despite the demonstrated benefits of rereading among the young, there is reason to question whether older readers habitually take advantage of the opportunity to reread. First, when younger and older readers are allowed more time for reading, it is the younger adults who show relatively better performance (Dixon, Simon, Nowak, \& Hultsch, 1982; Taub, 1979), suggesting that older readers do not effectively use the extra time, for example, by rereading. Second, older readers may be less likely to backtrack while reading text that raises problems. Zabrucky and Moore (1994) measured on-line processing and memory performance among younger and older adults reading texts containing inconsistencies. They showed that older readers were less likely to reread in the face of inconsistency. Using partial correlations, they showed that this age difference in reprocessing could account for age differences in memory.

In some ways, a failure among the elderly to take advantage of the opportunity to reread would be puzzling, since there are several significant demonstrations of agerelated declines in memory for content from the textbase (Dixon et al., 1982; Light \& Capps, 1986; Stine, Cheung, \& Henderson, 1995; Zelinski \& Gilewski, 1988). Such deficits appear to be, at least in part, due to a reduced level of effectiveness in the processes underlying textbase construction (Hartley et al., 1994; Stine \& Hindman, 1994; Stine-Morrow, Milinder, Pullara, \& Herman, 2001), so rereading might serve as an effective remedial strategy. However, there is also evidence that age deficits in performance may be exacerbated by a self-regulatory failure (Craik \& Anderson, 1999; Craik \& Jennings, 1992), in that older adults may not always adjust their attentional allocation, or reading strategies, to accommodate age-graded declines in processing capacity, leading to an impoverished text representation.

In part, this has been investigated using what might be called the resource allocation approach, in which multiple regression is used to partition reading times into time allotted to particular processes presumed to be important in constructing a representation of text meaning (e.g., Aaronson \& Scarborough, 1977; Graesser, Hoffman, \& Clark, 1980; Millis et al., 1998; Stine, 1990; StineMorrow, Milinder, et al., 2001; Zwaan et al., 1995). For example, reading time generally increases linearly as a function of the number of syllables (i.e., word length); by regressing reading time onto the number of syllables for each participant, we can estimate the time allocated for orthographic decoding (milliseconds/syllable) for each individual reader (Lorch \& Myers, 1990). Multiple regression can be used to extend this principle so as to estimate time allocation to the simultaneous demands of the array of processes used to construct meaning from a text. At least under some conditions, there is intraindividual consistency in these parameters across a 1-month interval (Stine-Morrow, Milinder, et al., 2001), suggesting that resource allocation in reading may be an individual difference of potential interest in understanding encoding processes during reading.

What are the resources in resource allocation? The assumption is that the self-regulated allocation of time to particular processes reflects attention to or effort in these computations, so that more time indicates a more thorough analysis of these features. There is evidence for this, for example, in the fact that the degree to which resources are allocated to wrap-up is predictive of subsequent memory performance (Haberlandt, Graesser, Schneider, \& Kiely, 1986; Miller \& Stine-Morrow, 1998; Stine-Morrow, Milinder, et al., 2001). Also, readers who show above-average memory and comprehension performance show patterns of resource allocation different from those of average or below-average readers (Morrow, Stine-Morrow, Leirer, Andrassy, \& Kahn, 1997; Stine, 1990; Stine-Morrow, Loveless, \& Soederberg, 1996; Stine-Morrow, Morrow, \& Leno, 2002). It is important to note that the use of the term resources in resource allocation (e.g., Graesser, 1981) is not the same construct as that used to refer to processing capacities, such as working memory or the activation available used to fuel language processing (e.g., Craik \& Simon, 1980; Just \& Carpenter, 1992; Salthouse, 1988). For example, there is little evidence that individual differences in measures of processing capacity (e.g., working memory) are positively related to resource allocation in reading (e.g., StineMorrow et al., 1996). Furthermore, if these were the same resources, one might expect that manipulations that draw working memory resources away from language processing (e.g., a simultaneous memory load) would reduce resource allocation in language processing. This does not appear to be the case (Smiler, Gagne, \& Stine-Morrow, 2003).

There have been several demonstrations of age differences in resource allocation. Older readers may allocate less time to the processing of the concepts described by the text, which would presumably reduce the quality of the textbase representation (Radvansky, Zwaan, Curiel, \& Copeland, 2001; Stine, 1990; Stine et al., 1995; StineMorrow et al., 1996). However, age differences in resource allocation in reading may not be merely quantitative (i.e., fewer resources devoted to textbase construction) but may be qualitative as well, with a growing number of studies suggesting that older readers are relatively more attuned to the situation model (Radvansky, 1999; Stine, Soederberg, \& Morrow, 1996). For example, Radvansky et al. (2001) asked younger and older adults to read historical narratives. Sector-by-sector reading times were collected. After reading, the participants performed a recognition task in which the type of probe was manipulated (verbatim, paraphrase, inference, or incorrect). Regression analyses used to decompose reading times into 
resources allocated to textbase and situation model processing showed that younger and older adults allocated time similarly, although older adults tended to allocate less time to new arguments (i.e., concepts; reflecting textbase processing) and more time to process the introduction of new discourse entities (reflecting situation model processing). Comprehension performance provided support for this interpretation: In a signal detection analysis, older readers showed poorer discrimination for surface and textbase probes (verbatim/paraphrase), but better discrimination for situation model probes (inference). Radvansky et al. suggested that among older readers, the surface and textbase representations are more fragilely constructed, so that they act as a scaffold for situation model construction but dissipate quickly (p. 154).

Other evidence for older readers' greater attention to discourse level features (such as the situation model) resides in the fact that they sometimes show an exaggerated serial position effect (i.e., relatively more time allocated earlier in the passage, to instantiate setting and characters; Stine-Morrow et al., 1996), which may indicate that older readers are more attentive to structure building (Gernsbacher, 1990). Effective older readers may also be differentially responsive to conventional story structure in allocating attention as they read narratives (Stine-Morrow, Miller, \& Leno, 2001). Finally, the on-line reading times of effective older readers sometimes reflect greater sensitivity to the spatial location of the protagonist in narratives (Morrow et al., 1997; StineMorrow et al., 2002), suggesting that effective older readers may be more likely to "inhabit" the narrative world. Collectively, these data suggest that resource allocation among older readers (particularly those who are ultimately successful in comprehension and/or memory) may be guided more by holistic properties of the discourse (e.g., narrative structure, or as properties of the situation model).

There are at least two different reasons why older readers might show such a shift toward holistic processing of discourse. First, this may be yet another example of age-graded increases in top-down processing (e.g., Speranza, Daneman, \& Schneider, 2000; Stine \& Wingfield, 1994), with age-graded declines in sensory processing and working memory driving a dependence on context. Another explanation is prompted by the proposal that affect is relatively more motivating for cognitive processing in late life (Carstensen \& Turk-Charles, 1994; Isaacowitz, Charles, \& Carstensen, 2000); assuming that situation model processing is integral to experiential and affective processing of language, older readers may give more weight to interpretive levels than to explicit content (e.g., Adams, Smith, Nyquist, \& Perlmutter, 1997).

Thus, the question of how aging changes what is accomplished in rereading is interesting on a number of levels. First, older readers' relative lack of attentiveness to textbase construction on a first reading would be expected to create an impoverished textbase representation. Such a deficiency in the textbase would be expected to produce a smaller rereading benefit for older readers. Whether they would be able to make up for this deficiency through rereading would depend on effective cognitive self-regulation. Assuming that older readers are sensitive to the lack of fidelity in the textbase representation and are able to effectively initiate the allocation of resources for repair, older readers would be expected to allocate relatively more attention to the text on a second reading to "fill in the gaps" in the conceptual representation (i.e., show less of a rereading benefit). Thus, age comparisons of rereading address the nature of the memory representation of text among older adults, as well as the utility of rereading as a compensatory vehicle. Also, the examination of age differences in rereading is informative with respect to the nature of situation model processing, allowing us to juxtapose findings that younger adults increase attention to situation model processing with rereading and that older adults are immediately more attentive to the situation model. The comparison of younger and older readers across successive encounters with a text allows us to examine whether textbase processing is a prerequisite for situation model development (as the data for younger readers alone would suggest).

There is one investigation that we know of in which age differences in rereading have been examined. Reasoning that rereading may be one way for older readers to circumvent processing limits, Harris, Rogers, and Qualls (1998) asked participants to read a series of texts and verify a set of statements testing comprehension/retention of information both explicitly stated and implied in the passage, and then to reread the passages and answer the same set of questions. They found that performance of both younger and older adults increased from reading to rereading, with younger and older readers showing similar levels of improvement. Both younger and older adults were faster in rereading than in reading, showing a rereading benefit. Interestingly, older adults showed relatively less facilitation in rereading, suggesting that they were taking differential advantage of the second reading to create a distinctive, elaborated representation of the text. We played off this line of research by using the resource allocation approach to examine the way in which reading time is allocated to particular computations during reading and rereading. In addition, in an effort to examine how adults regulate rereading only on the basis of their cognitive representations of the text (and not as a search for particular information queried at test), we assessed comprehension only after the second reading.

\section{EXPERIMENT 1 Rereading Scientific Expository Texts}

In the first experiment, we focused on age differences in the rereading of expository texts. We examined how readers allocate attentional resources to word, textbase, and situation model processing for this genre by selecting properties of the text segments representing each of these levels. Allocation to word-level processing was op- 
erationalized as changes in reading time as a function of syllable length (orthographic decoding) and word frequency (lexical access; cf. Haberlandt, 1984; Just \& Carpenter, 1980; Stine-Morrow, Milinder, et al., 2001). Allocation to textbase processes was operationalized as an increase in reading time with increases in the number of propositions and new concepts (organization and integration of textbase; cf. Graesser et al., 1980; Millis et al., 1998). Situation model processing was operationalized as the change in reading time as a function of segment importance (which is related to the causal connectivity of segments to the text as a whole; van den Broek, 1994; see also Millis et al., 1998) and (in light of arguments that situation model processing relies on perceptual symbols; Barsalou, 1999) the imageability of each segment. If the surface and textbase representations created by older readers are less elaborated on the first reading, we would expect them to show less of a rereading benefit than younger readers in these allocations. If situation model construction has priority for older readers, we would expect to see relatively greater allocation on the first reading than on the second.

\section{Method}

Participants. The participants were 42 community-dwelling elders (61-83 years of age, $M=74.31, S E=0.76)$ and 42 university students $(17-29$ years of age, $M=19.17, S E=0.38)$. Older participants had an advantage over the young on WAIS vocabulary $\left[M_{\mathrm{Y}}=47.7, S E=1.30 ; M_{\mathrm{O}}=59.3, S E=0.88 ; t(82)=7.43, p<\right.$ $.001]$. Because verbal ability and crystallized knowledge tend to show growth through adulthood (e.g., Ackerman \& Rolfhus, 1999), this difference is not uncommon between otherwise comparable samples. ${ }^{1}$ In addition, reading and listening span tasks were administered as a measure of verbal working memory (cf. Stine \& Hindman, 1994). In these tasks, participants read or listened to a series of sentences to make a true/false judgment after each sentence and then recalled the last word for each of the sentences at the end of the series. The number of sentences increased, and the score on the task was equal to the largest set size that the participant accurately completed plus a fractional value reflecting the proportion of words recalled on the subsequent level; our measure was an average across the two modalities. As is often found in studies of cognitive aging, younger adults had an advantage on this task $\left[M_{\mathrm{Y}}=\right.$ 4.60, $\left.S E=0.14 ; M_{\mathrm{O}}=3.41, S E=0.16 ; t(81)=5.61, p<.001\right]$.

Stimulus materials. Expository texts were excerpts from two reports that had appeared in American Scientist, one about the maternal habits of the burying beetle ("Coleopteran Child Care") and another about the causes and potential cures of baldness ("Gone Today, Hair Tomorrow"). The beetle passage contained 620 words and 34 sentences and had a Flesch-Kincaid (FK) reading level of 11.1. The hair passage contained 866 words and 54 sentences and had an FK reading level of 9.3. Each passage was divided into sectors (short sentences or clauses) for presentation. The beetle passage was presented in 61 sectors $(M=10.13$ words, $S D=2.84)$, and the hair passage was presented in 78 sectors $(M=11.13$ words, $S D=3.73$ ).

Each sector was coded with respect to (1) the total number of syllables, (2) the average log word frequency (Francis \& Kučera, 1982), (3) the number of new concepts introduced, (4) the number of propositions (Kintsch \& van Dijk, 1978), and (5) the serial position of the sector in the passage. Also coded were (6) importance of the sector and (7) imageability of the sector, based on reader ratings. To do this, the passages were presented to 48 university un- dergraduates, who first read each passage in its entirety and then rated each sector of the passage for its importance to the passage as a whole $(1=$ highly important $; 5=$ little to no importance $)$, and the imageability of the sector $(1=$ highly imageable; $5=$ difficult or impossible to image). Average ratings for each sector were thus used to code for these variables. Descriptive statistics for these variables are provided in Appendix A. This array of variables represented a range of text-processing operations but, at the same time, did not introduce problems of multicollinearity.

For each passage, eight statements were constructed that probed for information that was both explicitly stated in the text and implied. These verification statements were constructed so that half were consistent with the passage and half were inconsistent. For example, for the "Gone Today, Hair Tomorrow" passage, about the causes of baldness and research directed toward stimulating hair growth, the statement "It is the same pool of cells that mature into either skin cells or hair" (true) probed a fact contained in the passage, and the statement "A person suffering from alopecia totalis would have to shave more frequently" (false) probed an inference based on a discussion of one of the types of baldness.

Procedure. The entire session in which the participants were tested on vocabulary, working memory span, and reading tasks (for both of the experiments described in this article) lasted approximately $2 \mathrm{~h}$. Both reading and span tasks were presented using PowerLaboratory software (Chute \& Westall, 1997) on a Macintosh computer.

The participants read all the passages once, with the understanding that they would be given the opportunity to reread each one before being tested on comprehension. The comprehension probes were answered immediately after the second reading of each passage. Reading was self-paced, with noncumulative sector presentation controlled by a buttonpress. The participants were instructed to read at a comfortable pace so that they would be able to answer questions about the passages later. Within text type, passages were presented in a single random order; the order of text type was counterbalanced across participants.

\section{Results and Discussion}

Comprehension performance. There was a small but reliable age difference in the proportion of comprehension questions answered correctly, which favored the older readers $\left[M_{\mathrm{Y}}=.77, S E=.14 ; M_{\mathrm{O}}=.83, S E=.14\right.$; $t(82)=2.93, p<.01 ; r(84)=.312, p<.01]$, although this relationship was no longer significant when vocabulary was partialled out $[r(81)=-.07]$.

Global effects of rereading. To examine the facilitation in rereading at a global level within each age group, we regressed median sector reading times at the second reading onto those at the first reading. Assuming that reading time is a reflection of the computations conducted in linguistic analysis, the correlation of segment reading times between reading and rereading suggests a gross qualitative similarity in processing across the two encounters. The slopes of these functions, on the other hand, reflect the relative gain in speed for segments of increasing complexity, with a disproportionate gain in efficiency for more complex segments.

In fact, median sector reading and rereading times showed an orderly relationship within each age group ( $r=.916$ for the old and $r=.914$ for the young), showing rank order stability in global processing demands at the two readings, regardless of age. However, the slope in this analysis was shallower for the younger readers $(y=.694 x+135)$ than it was for the older ones $[y=$ 
$.783 x+154 ; t(137)=2.24, p<.05]$. The substance of this finding held even when the analysis was conducted on the raw reading times for each individual (in which reading time estimates were much less reliable) and rereading slope was treated as an individual difference variable. Older readers' segment reading times tended to be more tightly related across readings than those of the young $\left[M_{\mathrm{Y}}=.33, S E=.026 ; M_{\mathrm{O}}=.39, S E=.025 ; t(82)=\right.$ $1.76, p=.081]$, and their slopes were greater $\left[M_{\mathrm{Y}}=.30\right.$, $S E=.030 ; M_{\mathrm{O}}=.40, S E=.030 ; t(82)=2.35, p<$ $.025]$. The age difference in slopes is consistent with the idea that the younger adults had processed the text more thoroughly on the first pass and, therefore, required less thorough analysis at the second reading. The nature of this facilitation is explored at a process level, using the resource allocation approach.

Reading time allocation. Table 1 provides the mean allocation parameters, mean variance accounted for, and mean intercepts collapsed across age at the first and second readings. These values are the mean regression coefficients from the individual regressions of reading times onto text features. As raw regression coefficients (not standardized betas), they represent the time allocated (in milliseconds) per unit change in the text feature.

All the parameters were significantly different from zero on at least one of the readings. This general pattern of allocation parameters suggests that readers were reliable in allocating time for orthographic decoding (syllables), for elaborating the meaning of low-frequency words, for instantiating new concepts (significant only on the first reading), in constructing a propositional textbase, in attempting a visual representation for low-imagery segments (significant only on the second reading), in elaborating on the meaning of segments of greater rated importance, and in structure building early in the text so as to garner contextual facilitation later in the text. Thus, this constellation of parameters is consistent with earlier work (e.g., Millis et al., 1998; Zwaan et al., 1995) showing that reading time is generally sensitive to the processing demands needed to construct representations at the level of the word, the textbase, and the situation model.
There was a significant reduction in variance accounted for in reading times with our text parameters on the second reading $[F(1,82)=19.52, p<.001]$. There were no age differences in variance accounted for $(F<1)$, nor did the rereading effect on variance accounted for vary with age $(F<1)$. Older adults did show larger intercepts at both the first $\left(M_{\mathrm{Y}}=1,804 \mathrm{msec}, S E=332 ; M_{\mathrm{O}}=\right.$ $3,551 \mathrm{msec}, S E=332)$ and the second $\left(M_{\mathrm{Y}}=1,715 \mathrm{msec}\right.$, $\left.S E=332 ; M_{\mathrm{O}}=3,085 \mathrm{msec}, S E=332\right)$ reading $\mathrm{s}$ $[F(1,82)=19.08, p<.001]$, reflecting age differences in sensorimotor slowing (and possibly, computation time not captured by our selected text variables). Intercepts did not vary with rereading $(F<1)$ or differentially across readings for the young and the old ( $F<1$ for the interaction).

The allocation parameters in Table 1 also suggest that there was a shift in responsiveness to processing demands from reading to rereading. To examine whether this was the case and whether it was different for the young and the old, we simplified our analysis by standardizing the allocation parameters and creating composite variables reflecting the relative resource allocation to word-level processing (the average of the $z$-score for the syllables parameter and the negative $z$-score for the word frequency parameter), textbase processing (the average of the $z$-scores for the propositions and new concepts parameters), and situation model processing (the average of the $z$-score for imagery and the negative $z$-score for importance). This approach to creating composite indices provided a way to operationalize the theory of discourse understanding articulated earlier in this article, using measures that are presumably more reliable than any one allocation parameter would be. Not only does this simplify the presentation of our findings, but it allows a more straightforward test of the hypothesis that older adults are more immediately attentive to the situation model (Radvansky, 1999). The theoretical status of the serial position effect (the increased reading speed with progress through the text) is ambiguous, with some researchers arguing that this reflects the mental model or structure building followed by subsequent facilitation (Gernsbacher, 1990; Haberlandt, 1984; Little, 2001;

Table 1

Allocation Parameters (Regression Coefficients in Milliseconds) on First and Second Readings of Expository Passages

\begin{tabular}{|c|c|c|c|c|}
\hline \multirow{2}{*}{$\begin{array}{l}\text { Allocation } \\
\text { Parameter }\end{array}$} & \multicolumn{2}{|c|}{ First Reading } & \multicolumn{2}{|c|}{ Second Reading } \\
\hline & Coefficient & $t$ value & Coefficient & $t$ value \\
\hline Syllables & 141.8 & $19.705^{* * * *}$ & 106.5 & $14.846^{* * * *}$ \\
\hline Log word frequency & -187.2 & $-3.803^{* * * *}$ & -163.5 & $-3.054^{* * *}$ \\
\hline New concepts & 143.4 & $5.186^{* * * *}$ & 48.2 & $1.957^{*}$ \\
\hline Propositions & 54.7 & $3.532^{* * * *}$ & 72.4 & $4.610^{* * * *}$ \\
\hline Imagery & 67.3 & $1.704^{*}$ & 137.9 & $3.242^{* * *}$ \\
\hline Importance & -471.2 & $-8.757^{* * * *}$ & -495.9 & $-7.883^{* * * *}$ \\
\hline Serial position & -3.6 & $-2.656^{* * *}$ & -5.7 & $-4.668^{* * * *}$ \\
\hline Adjusted $R^{2}$ & .299 & $20.963^{* * * *}$ & .238 & $16.275^{* * * *}$ \\
\hline Constant & $2,677.2$ & $10.602^{* * * *}$ & 2,399.9 & $8.664^{* * * *}$ \\
\hline
\end{tabular}

Note-A significant $t$ value indicates that a parameter was significantly different from zero. ${ }^{*} p<.1 .{ }^{* * *} p<.01 .{ }^{* * * *} p<.001$. 
Stine-Morrow, Miller, \& Leno, 2001) and others arguing that it reflects integration at the textbase level (Radvansky et al., 2001). In fact, the serial position effect could have contributions from both the textbase and the situation model. Therefore, we did not include it in our composite scores but, rather, analyzed it separately. Cell means for all raw allocation parameters are presented in Appendix $B$. The three indices were analyzed in a 2 (age) $\times$ 2 (time: first reading or second reading) $\times 3$ (level: word, textbase, or situation model) repeated measures analysis of variance (ANOVA).

Consistent with Millis et al. (1998), resource allocation to word and textbase features decreased with rereading (for word processing, $M_{\mathrm{T} 1}=.142, S E=.067$, and $M_{\mathrm{T} 2}=-.142, S E=.075$; for textbase processing, $M_{\mathrm{T} 1}=$ $.066, S E=.080$, and $\left.M_{\mathrm{T} 2}=-.066, S E=.081\right)$, but allocation to situation model processing increased $\left[M_{\mathrm{T} 1}=\right.$ $-.058, S E=.078 ; M_{\mathrm{T} 2}=.058, S E=.082 ; F(2,164)=$ $4.59, p<.02$, for the time $\times$ level interaction]. Allocation was different, however, for the younger and the older readers. The age $\times$ level interaction was marginally significant $[F(2,164)=2.69, p=.078]$, and the age $\times$ time $\times$ level interaction was reliable $[F(2,164)=3.49$, $p<.05]$. The two-way interaction reflects a trend toward greater allocation among the old than among the young to both word and situation model processing, but a minimal age difference in allocation to textbase processing.

The three-way interaction, suggesting that age differences in rereading benefit depended on the type of processing, is shown in Figure 1. Whereas the younger adults showed a rereading benefit at the word level $(p<.01)$, the older adults did not (left panel). On the basis of the logic of the window-into-reading approach introduced earlier, this finding suggests that older readers' analysis of word meanings was less thorough on the first reading, or that they retained less word information, so that their word-level analysis needed to be more thorough on the second pass. Although word decoding and lexical access are ordinarily thought of as being immune to age differ- ences, processing of novel words can be resource consuming and create challenges for elderly readers (McGinnis $\&$ Zelinski, 2000). These texts were scientific texts containing technical language and a rather arcane vocabulary, and it is perhaps not surprising that the older adults showed less facilitation than the young in word-level processing on the second pass.

Situation model processing (shown in the right panel of Figure 1) also showed differential change with rereading across age groups, but in a very different pattern. Whereas the younger adults tended to increase their allocation to the situation model on the second reading, relative to the first $(p=.10)$, the older adults tended to allocate more attention to situation model features than the young did on the first reading $(p=.10)$ but showed no change from the first to the second encounter. At the level of individual allocation parameters, the older adults' reading times were more sensitive to importance on the first reading than were those of the young $[F(1,82)=$ $5.43, p<.025]$. So for these expository texts, the older readers allocated more resources to word and situation model processing, with disproportionate effort to words on the second encounter and disproportionate effort to the situation model on the initial encounter.

In textbase processing (shown in the middle panel of Figure 1), the older readers did not differ significantly from the young in allocation on the first reading $(p>.10)$. However, they decreased their allocation from reading to rereading $(p<.025)$, whereas the younger adults did not. According to the logic of the window-into-reading approach, this pattern might suggest that on the first pass, the older adults constructed a strong textbase representation and were, therefore, showing a rereading benefit (which was not evident among the young). However, the empirical literature is fairly clear in showing an age-graded reduction in the efficiency of textbase processing (e.g., Hartley et al., 1994; Stine \& Hindman, 1994), and the older adults did not allocate more time than the young did to this level of processing on the first

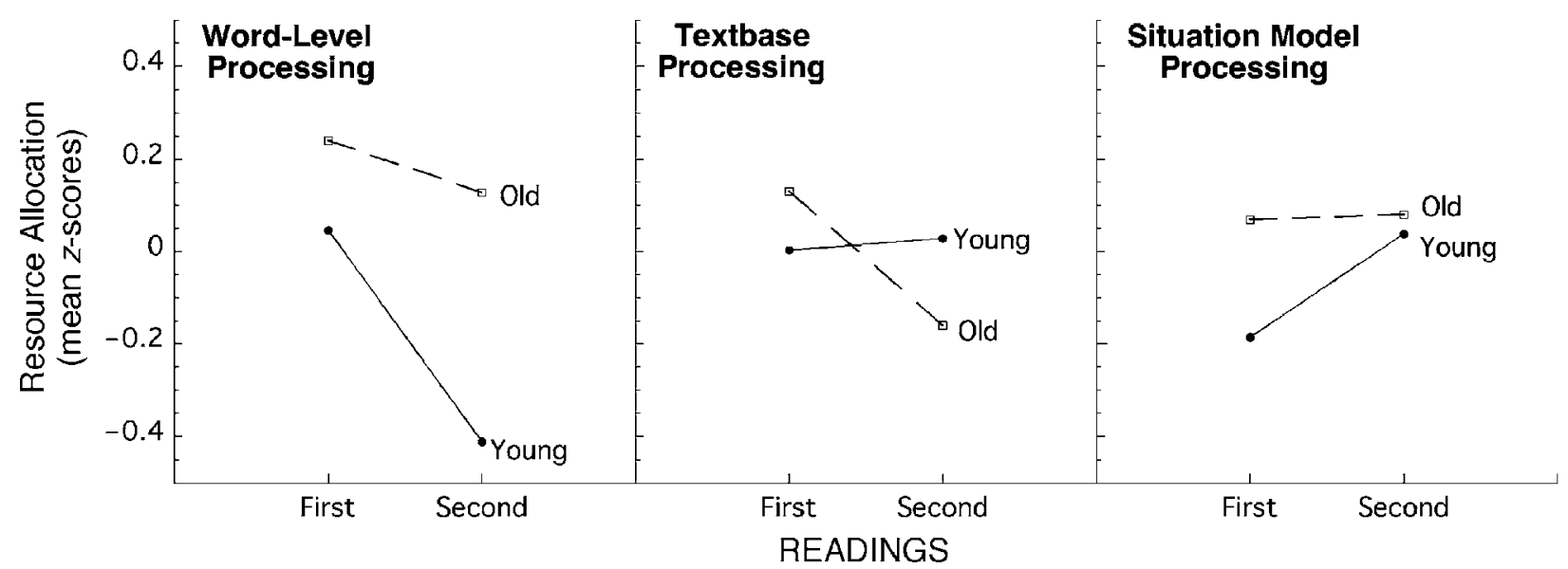

Figure 1. Age differences in resource allocation shifts in rereading expository texts. 
reading. Therefore, this explanation does not seem plausible to us. Another possibility is that the decrease in attentional allocation to the textbase among the elderly was a self-regulatory failure, in which the older readers were unable to recruit the resources needed to compensate for an impoverished representation (cf. Dunlosky \& Connor, 1997). This is possible, but recall that the older adults' comprehension was at least as good as that of the young. In light of the older readers' greater allocation to word-level and situation model processing, a third possibility is that this decrease in attentional allocation to the textbase may have been an instance of elected neglect, an implicit choice to selectively allocate resources where they will pay off (Metcalfe, 2002; Miles \& StineMorrow, in press). The latter account is, of course, speculative but may be more likely than the other two.

Finally, the readers showed reliable serial position effects on both readings. There was no systematic change as a function of rereading $[F(1,82)=1.37]$, age $(F<1)$, or a combination of the two $(F<1)$.

Collectively, these data suggest that the older readers achieved high levels of comprehension through allocation policies different from those of the young. For these science-based texts, the older readers allocated relatively more time to word-level computations than did the young on the second reading. On the other hand, the older readers' greater responsiveness to situation model features (especially, sector importance) on their initial encounter with the text is consistent with the notion that older readers are more attentive to the more holistic properties of a discourse than are the young (e.g., Radvansky, 1999). Perhaps, the representation garnered from this attention to word and situation model processing enabled the older readers to achieve levels of comprehension comparable to those of the young with a less thorough analysis of the textbase.

\section{EXPERIMENT 2 Rereading Narrative Texts}

In the second experiment, we focused on the allocation shift in rereading narrative prose. In measuring resource allocation, we retained most of the variables that we had used in assessing responsiveness to expository texts: syllables, word frequency, new concepts, propositions, serial position, and imageability. In addition, because narrative processing is qualitatively different from expository processing (e.g., in following the here-now point of a protagonist through an imagined world), we also coded for spatial discontinuities (e.g., Morrow, Greenspan, \& Bower, 1987; Stine-Morrow et al., 2002; Zwaan et al., 1995). ${ }^{2}$

\section{Method}

The participants were the same as in Experiment 1. They read four narratives. Two were folk tales drawn from Chinen's (1992) tales of midlife, "The Lute Player" and "The Magic Towel." Both of these are light, well-structured narratives with a clear protagonist and conventional episodic story structure. The other two were short stories written by Ernest Hemingway (1925/1966), "On the Quai at Smyrna" and "The Old Man at the Bridge." Both of these were inspired by his war experiences and are harsh, sometimes gruesome, depictions of what he saw of the Greco-Turkish and Spanish civil wars as a reporter. These stories do not follow conventional episodic story structure, although each has a protagonist, and as is typical for Hemingway, they were written with short, concrete sentences. At least intuitively, it was easy to grasp the unfolding situation in each of the folk tales; this was not true for the Hemingway stories.

"The Lute Player" contained 866 words and 72 sentences, and had an FK reading level of 5.2. "The Magic Towel" was 630 words and 47 sentences long, with an FK reading level of 4.4. "The Lute Player" was presented in 85 sectors $(M=10.2$ words, $S D=3.5)$, and "The Magic Towel" was presented in 59 sectors $(M=10.7$ words, $S D=3.4$ ). "The Old Man" contained 762 words and 65 sentences, and had an FK reading level of 3.6. "The Quai" contained 731 words and 60 sentences and had an FK reading level of 3.8. The "Old Man" story was presented in 76 sectors $(M=10.0$ words, $S D=3.9)$, and the "Quai" story was presented in $72 \operatorname{sectors}(M=$ 10.1 words, $S D=3.9$ ).

Each sector was coded with respect to (1) total number of syllables, (2) average log word frequency, (3) number of new concepts introduced, (4) number of propositions, (5) serial position of the sector in the passage, and (6) imageability of the sector (as described earlier). In addition, segments were dummy coded for the (7) presence of spatial continuity. Descriptive statistics for these variables for each type of narrative are presented in Appendix A. Comprehension probes were constructed as described in Experiment 1. For example, in "The Lute Player," a story about a queen who dresses up as a minstrel to gain access to the court of an evil lord who has captured the king, the statement "In order to search for her husband, the Queen disguised herself in the simple peasant clothes of a minstrel" (true) probed understanding of an event explicitly described; the statement "The King was apparently a calm man, not easily enraged" (false) was an inference based on the actions of the king throughout the story.

\section{Results and Discussion}

Comprehension performance. Collapsing across the folk tales and the Hemingway short stories, there were no age differences in performance $(F<1)$. Comprehension questions were correctly answered more often for the folk tales than for the Hemingway stories $[F(1,82)=$ $74.04, p<.001]$. The age $\times$ genre interaction was significant $[F(1,82)=11.22, p<.001]$, reflecting an advantage for elders in comprehending the Hemingway stories $\left(M_{\mathrm{Y}}=.78, S E=.02 ; M_{\mathrm{O}}=.81, S E=.01\right)$, but a young adult advantage for the folk tales $\left(M_{\mathrm{Y}}=.89\right.$, $\left.S E=.01 ; M_{\mathrm{O}}=.86, S E=.01\right)$.

Global effects of rereading. As in the case of expository passages, median reading times across reading and rereading were highly related within each age group $(r=$ .942 for the old and $r=.925$ for the young). Also, as in the previous analysis, the slope was shallower for the younger readers $(y=.682 x+101)$ than it was for the older ones $[y=.820 x-34 ; t(290)=5.91, p<.01]$.

A 2 (age) $\times 2$ (genre) repeated measures ANOVA on individual reading-rereading time correlations showed that the Hemingway stories yielded a more similar allocation across readings than did the folk tales $\left[M_{\mathrm{F}}=.36\right.$, $S E=.017 ; M_{\mathrm{H}}=.49, S E=.015 ; F(1,82)=45.51, p<$ 
$.001]$. Although there was no overall age difference $(F<1)$, there was an age $\times$ genre interaction $[F(1,82)=$ $16.61, p<.001]$, reflecting the fact that the younger adults showed greater rank order stability in allocating time to the folk tales than to the Hemingway stories $\left(M_{\mathrm{F}}=.54, S E=.024 ; M_{\mathrm{H}}=.44, S E=.022\right)$, whereas the older adults showed greater rank order stability for the Hemingway stories $\left(M_{\mathrm{F}}=.33, S E=.024 ; M_{\mathrm{H}}=.54, S E=\right.$ $.022)$. The ANOVA on the regression weights showed significant main effects for genre $[F(1,82)=42.42, p<$ $.001]$ and age $[F(1,82)=5.66, p<.02]$ that were moderated by the two-way interaction $[F(1,82)=10.39, p<$ $.001]$. The younger and the older adults showed similarly shallow slopes for folk tales $\left(M_{\mathrm{Y}}=.32, S E=.029\right.$; $\left.M_{\mathrm{O}}=.33, S E=.029\right)$, with the older readers showing a disproportionately larger slope for the Hemingway stories $\left(M_{\mathrm{Y}}=.39, S E=.028 ; M_{\mathrm{O}}=.54, S E=.028\right)$. In other words, both the younger and the older adults allocated more time to reprocessing difficult segments in the Hemingway stories (relative to the folk tales), but commensurate with comprehension scores, the older adults allocated relatively more effort in rereading the Hemingway stories than the young did.

Reading time allocation. Table 2 shows the allocation parameters, variance accounted for, and regression constants for the narratives collapsed across age and genre at the first and second readings. Text variables accounted for less variance in reading time on the second reading than on the first $[F(1,82)=71.68, p<.001]$. A greater proportion of variance was accounted for in reading times for the Hemingway stories than for the folk tales $\left[M_{\mathrm{F}}=.283, S E=0.01 ; M_{\mathrm{H}}=.375, S E=0.01 ; F(1,82)=\right.$ $71.98, p<.001]$. Although there was no age difference overall $(F<1)$, the age $\times$ genre interaction was significant $[F(1,82)=10.96, p<.001]$, such that among younger adults, more variance in reading times was accounted for when reading folk tales than when reading Hemingway stories $\left(M_{\mathrm{F}}=.308, S E=0.02 ; M_{\mathrm{H}}=.365\right.$, $S E=0.02$ ), whereas among older readers, more variance was accounted for when they were reading the Hemingway stories $\left(M_{\mathrm{F}}=.257, S E=0.02 ; M_{\mathrm{H}}=.386, S E=\right.$ $0.02)$. Finally, there was a greater drop in variance ac- counted for with rereading for folk tales $\left(M_{\mathrm{T} 1}=.346\right.$, $\left.S E=0.01 ; M_{\mathrm{T} 2}=.219, S E=0.01\right)$ than for the Hemingway stories $\left[M_{\mathrm{T} 1}=.416, S E=0.01 ; M_{\mathrm{T} 2}=.335\right.$, $S E=0.01 ; F(1,82)=5.17, p<.03$, for the time $\times$ genre interaction]. Neither age nor genre nor rereading significantly affected the regression constants for the narratives (all $F \mathrm{~s}<1$ ).

As with the expository passages, the readers were reliable in allocating time for orthographic decoding (syllables), for elaborating on the meaning of low-frequency words, and for instantiating new concepts and building the propositional textbase. The readers of these narratives were reliable, at both the first and the second readings, in reducing reading speed for low-imagery sectors, unlike for expository passages in the first experiment, in which imagery did not affect reading time allocation until the second reading. The readers also slowed at both the first and the second readings in the face of spatial discontinuity. Surprisingly, the effects of serial position were only marginally significant at the first reading and reversed direction at the second reading, indicating that the readers increased their reading speed through the passage on the first reading but then slowed down through the passage on the second reading.

As with expository passages, the allocation parameters in Table 2 suggest a shift toward less processing of word- and textbase-level features with rereading. To explore this, as well as to determine whether these patterns varied with age and narrative structure, we again created composite variables to reflect word (syllables and word frequency), textbase (new concepts and propositions), and situation model (imagery and spatial discontinuity) processing. These were analyzed in a 2 (age) $\times 2$ (genre: folk or Hemingway) $\times 2$ (time: first reading or second reading) $\times 3$ (level) repeated measures ANOVA.

Collapsing across the other independent variables, there were no age differences in overall allocation $[F(1,82)=$ 1.63]. Allocation was greater for the Hemingway stories than for the folk tales $[F(1,82)=10.55, p<.001]$ and for the first reading than for the second reading $[F(1,82)=$ $24.53, p<.001]$, but these effects were moderated in a series of interactions.

Table 2

Allocation Parameters (Regression Coefficients in Milliseconds) on First and Second Readings of Narrative Passages

\begin{tabular}{lcccrr}
\hline \multirow{2}{*}{$\begin{array}{c}\text { Allocation } \\
\text { Parameter }\end{array}$} & \multicolumn{2}{c}{ First Reading } & & \multicolumn{2}{c}{ Second Reading } \\
\cline { 2 - 3 } \cline { 5 - 6 } & Coefficient & $t$ value & & Coefficient & $t$ value \\
\hline Syllables & 132.2 & $26.138^{* * * * *}$ & & 105.1 & $22.814^{* * * *}$ \\
Log word frequency & -267.8 & $-12.001^{* * * *}$ & & -191.5 & $-5.785^{* * * *}$ \\
New concepts & 260.4 & $11.374^{* * * *}$ & & 174.8 & $8.020^{* * * *}$ \\
Propositions & 90.3 & $12.800^{* * * *}$ & & 68.8 & $8.321^{* * * *}$ \\
Imagery & 155.8 & $7.238^{* * * *}$ & & 132.1 & $5.545^{* * * *}$ \\
Spatial discontinuity & 191.4 & $8.285^{* * * *}$ & & 190.5 & $6.331^{* * * *}$ \\
Serial position & -1.1 & $-1.893^{*}$ & & 2.2 & $3.454^{* * * *}$ \\
\multicolumn{1}{c}{ Adjusted $R^{2}$} & .381 & $30.057^{* * * *}$ & & .277 & $24.846^{* * * *}$ \\
Constant & $1,028.0$ & $10.680^{* * * *}$ & & $4,590.1$ & 1.162 \\
\hline
\end{tabular}

Note-A significant $t$ value indicates that a parameter was significantly different from zero. ${ }^{*} p<.1 .{ }^{* * * *} p<.001$. 
The time $\times$ level interaction $[F(2,164)=5.87, p<.01]$ was partially consistent with the notion of a rereading shift from lower order to higher order discourse features. Collapsing across age, the allocation to word and textbase processing decreased with rereading (for words, $M_{\mathrm{T} 1}=.147$, $S E=.048 ; M_{\mathrm{T} 2}=-.147, S E=.060$; for textbase, $M_{\mathrm{T} 1}=$ $\left..132, S E=.053 ; M_{\mathrm{T} 2}=-.132, S E=.064\right)$, whereas the allocation to the situation model did not change $\left(M_{\mathrm{T} 1}=\right.$ $\left..021, S E=.052 ; M_{\mathrm{T} 2}=-.021, S E=.067\right)$. This two-way interaction was moderated by both genre and age.

The genre $\times$ time $\times$ level interaction $[F(2,164)=$ $5.65, p<.01]$ reflects the fact that for the folk tales, word and textbase processing were at least somewhat facilitated with rereading (for words, $M_{\mathrm{T} 1}=-.124, S E=$ $.053, M_{\mathrm{T} 2}=-.273, S E=.081, p=.083$; for textbase, $M_{\mathrm{T} 1}=.203, S E=.062 ; M_{\mathrm{T} 2}=-.061, S E=.070, p<$ .001 ; for situation model, $M_{\mathrm{T} 1}=.068, S E=.057 ; M_{\mathrm{T} 2}=$ $-.068, S E=.070, p=.138$ ), whereas for the Hemingway stories only word-level processing was facilitated (for words, $M_{\mathrm{T} 1}=.417, S E=.073 ; M_{\mathrm{T} 2}=-.021, S E=$ $.080, p<.001$; for textbase, $M_{\mathrm{T} 1}=.061, S E=.070$; $M_{\mathrm{T} 2}=-.014, S E=.073, p>.2$; for situation model, $M_{\mathrm{T} 1}=-.027, S E=.093 ; M_{\mathrm{T} 2}=.026, S E=.101, p>$ $.2)$. The relatively greater facilitation of textbase processing for the folk tales is consistent with the observation that the content of these stories was easier to grasp immediately than that of the Hemingway stories. The readers were more engaged in developing the textbase for the more accessible folk tales on the first reading, but for the Hemingway stories they were still working to construct a textbase on the second reading.

The age $\times$ time $\times$ level interaction $[F(2,164)=3.57$, $p<.05]$, depicted in Figure 2, suggests an age difference in the shift of allocation policy with rereading. Both the younger and the older readers showed a rereading benefit in word and textbase processing, but this effect was greater among the young than among the old. This pattern was reversed for situation model processing: The older readers' allocation to situation model features was relatively high on the first reading and then decreased with rereading, whereas the younger readers' allocation showed a slight (but nonsignificant) increase. On the basis of the logic of the window-into-reading approach, these data are consistent with the idea that younger readers create durable word- and textbase-level representations on a first reading that lead to facilitated processing at these levels and provide a scaffold for the construction of a situation model (however, we failed to replicate the significant increase in attention to situation model processing from Experiment 1; see also Zwaan et al., 1995). The reduced rereading benefit for word and textbase processes among the older readers suggests that these representations may not have been as available to facilitate rereading. As with the expository texts, the older readers allocated relatively more attention to the situation model on the first encounter, suggesting that situation model construction may have a higher priority for older readers.

The age $\times$ genre interaction $[F(1,82)=21.23, p<$ $.001]$ and the age $\times$ genre $\times$ level interaction depicted in Figure $3[F(2,164)=6.33, p<.01]$ were also significant. These interactions suggest that the older readers allocated relatively more resources to the Hemingway stories, whereas the younger readers allocated relatively more resources to the folk tales. This pattern was the most pronounced, however, for the situation model. Thus, the older readers appear to have achieved their relatively better comprehension of the Hemingway stories through engagement at all levels of processing.

Collectively, these data address the issue of the textbasesituation model shift in rereading. These data support the notion that rereading involves less thorough processing of the textbase, and not surprisingly, this principle appears to be most applicable to easier, more well structured stories. The Hemingway stories were concrete in detail but were more challenging than the folk tales in guiding the reader toward construction of a situation model. Even though the textbase and the situation model are separable constructs (e.g., Zwaan et al., 1995), a clear situation model can facilitate processing of the textbase (Miller \& Stine-Morrow, 1998; Sharkey \& Sharkey, 1987). This may help explain

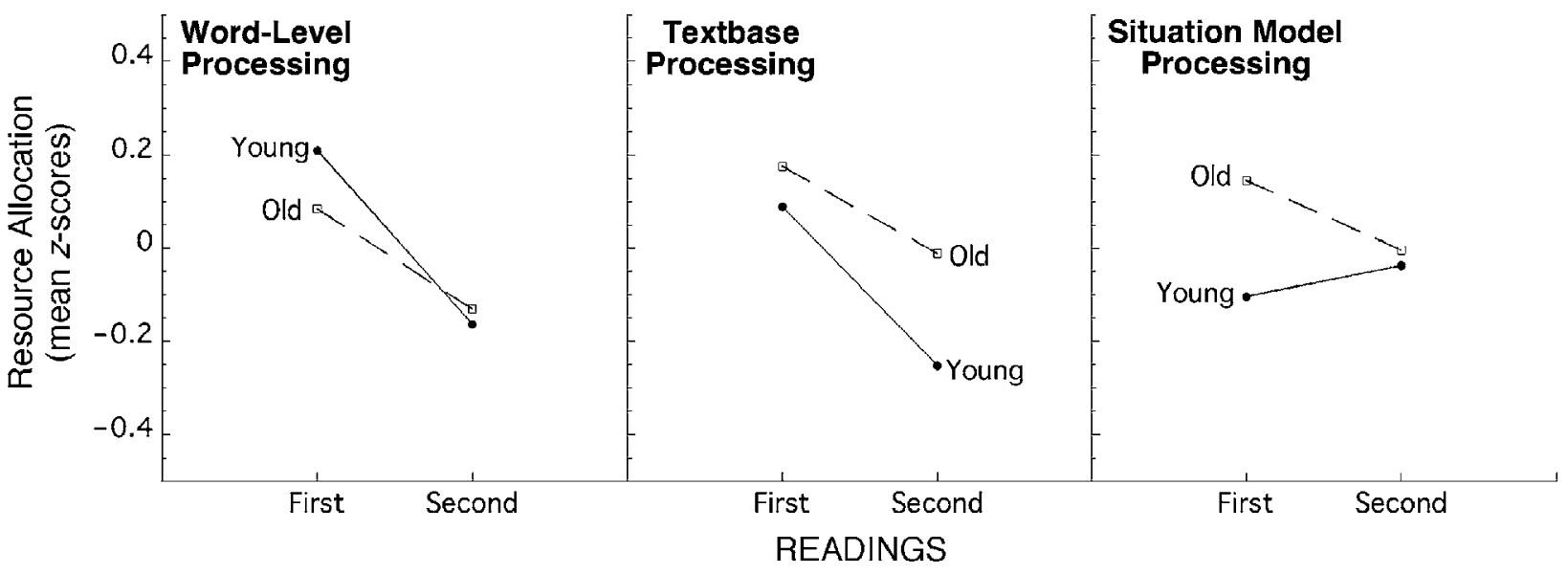

Figure 2. Age differences in resource allocation shifts in rereading narrative texts. 


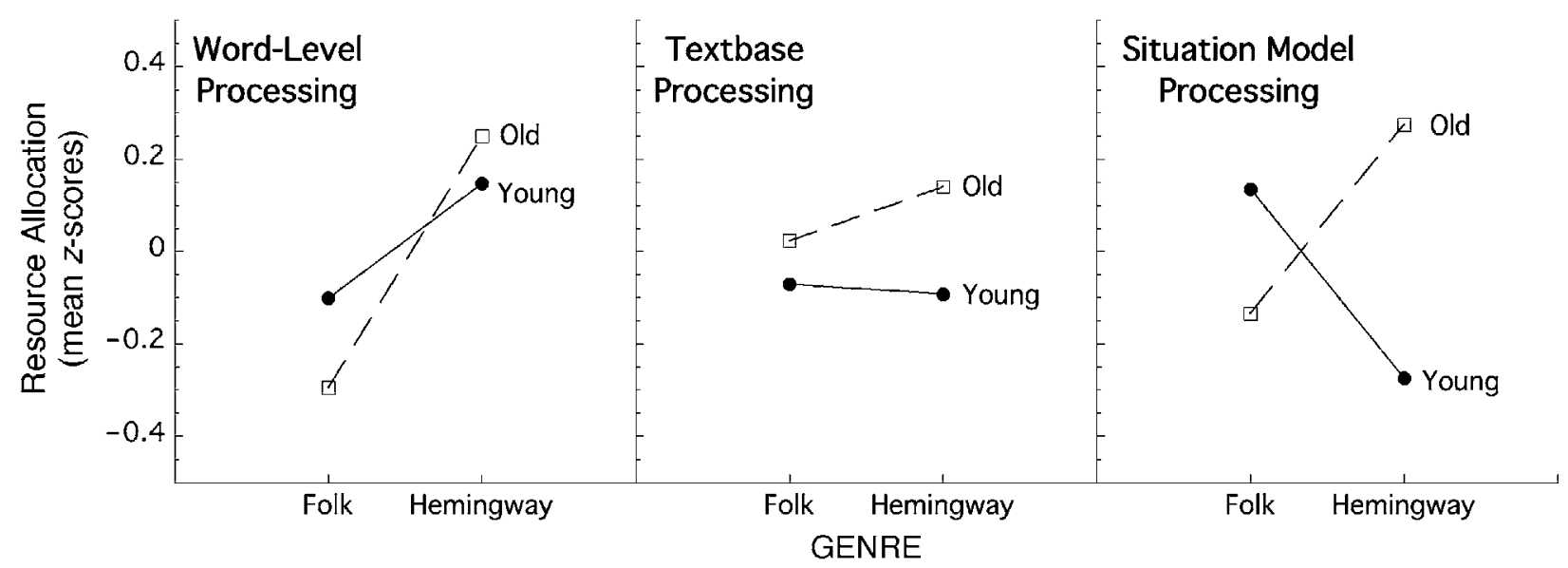

Figure 3. Age differences in resource allocation to narrative texts as a function of genre.

why the participants allocated less time to propositional coding in rereading the folk tales, but no such facilitation in rereading the Hemingway stories; in rereading the more challenging Hemingway stories, the readers were still working hard to develop a semantic representation even at the textbase level. On the other hand, we found little support in this study for the notion that attention to the situation model actually increases with rereading.

The analysis of serial position effects showed a reliable shift toward less negative serial position effects on the second reading - that is, less structure building with rereading $[F(1,82)=16.42, p<.001]$. This is consistent with Little's (2001) finding of the elimination of serial position effects for familiar passages. The serial position effects also varied with narrative genre $[F(1,82)=37.76$, $p<.001]$. Folk tales generated a negative serial position effect $(M=-1.83, S E=0.54)$, reflecting structure building, whereas the ill-structured Hemingway stories generated a positive serial position effect $(M=2.19, S E=0.63)$, suggesting that rather than increasing reading speed as a schema developed, readers were slowing down in an attempt to find one. None of these effects varied with age.

\section{COMBINED ANALYSIS \\ Effects of Resource Allocation on Performance}

We used a regression analysis on the combined data from the two experiments to evaluate the extent to which the allocation policy contributed to comprehension. In particular, we were interested in whether a relatively more extensive analysis on rereading and whether allocation to word, textbase, and situation model features were predictors of performance. To operationalize the allocation of effort to reprocessing, we used the rereading slope for each participant (assuming that the greater the slope, the greater the time allocated to reprocess the relatively more difficult text segments), averaging across the three genres. Across genre, these slopes formed a reasonable scale (Cronbach's $\alpha=.62$ ). To operationalize allocation to text features, we averaged the composites across genre and opportunities for reading. Thus, a hierarchical regression analysis was used to predict overall comprehension from rereading slope, indices of word, textbase, and situation model allocation, vocabulary, average working memory span, and age. As the most proximal variable to performance, variables reflecting the allocation policy were entered first; vocabulary and span were entered together in the second step, and age was entered last. Intercorrelations among these measures are presented in Table 3; the results from the hierarchical regression are shown in Table 4.

Altogether, allocation policy and ability measures predicted $32.6 \%$ of the variance in comprehension performance, with allocation policy and ability measures contributing about equally. Rereading slope was a significant predictor of comprehension, suggesting that those who

Table 3

Correlations Among Measures of Ability, Resource Allocation, and Comprehension Performance

\begin{tabular}{llllllll}
\hline & Age & Voc & WM & Word & TB & SM & RR \\
\hline Vocabulary & $.65^{* * * *}$ & & & & & & \\
Mean working memory span & $-.55^{* * * *}$ & $-.23^{* *}$ & & & & & \\
Word allocation & .13 & -.08 & -.17 & & & & \\
Textbase allocation & .12 & .05 & -.10 & $.30^{* * *}$ & & & \\
Situation model allocation & $.19^{*}$ & $.20^{*}$ & -.10 & $.35^{* * * *}$ & $.27^{* *}$ & & \\
Rereading slope & $.31^{* * *}$ & $.27^{* *}$ & $-.32^{* * *}$ & .17 & .06 & .10 & \\
Mean comprehension & .15 & $.47^{* * * *}$ & .01 & .03 & .02 & $.39^{* * * *}$ & $.24^{* *}$ \\
\hline
\end{tabular}

${ }^{*} p<.1 . \quad{ }^{* *} p<.05 . \quad{ }^{* * *} p<.01 . \quad{ }^{* * * *} p<.001$. 
Table 4

Hierarchical Regression to Predict Comprehension Performance

\begin{tabular}{lccc}
\hline \multicolumn{1}{c}{ Variable } & $\begin{array}{c}\text { Standardized } \\
\beta\end{array}$ & $t$ Value & $\begin{array}{c}\text { Increment in } \\
\text { Adjusted } R^{2}\end{array}$ \\
\hline Word allocation & -.137 & -1.24 & \\
Textbase allocation & -.070 & -.66 & \\
Situation model allocation & .437 & $4.04^{* * * *}$ & \\
Rereading slope & .221 & $2.19^{* *}$ & .180 \\
Working memory span & .192 & $1.84^{*}$ & \\
Vocabulary & .407 & $3.88^{* * * *}$ & .146 \\
Age & -.136 & 1.24 & .006 \\
${ }^{*} p<.1 .^{* *} p<.05 .^{* * * *} p<.001$. & &
\end{tabular}

allocated extra effort to rereading the most difficult segments tended to show higher levels of comprehension. In addition, allocation to the situation model was predictive of performance, consistent with the view that it is situation model processing that is necessary for true learning (e.g., Kintsch, 1994). Even though allocations to word and textbase processing were not direct predictors of performance, both of these were correlated with allocation to situation model processing (see Table 3), supporting the idea that surface and textbase representations provide a scaffold for situation model construction (Radvansky et al., 2001). With the effects of allocation policy partialled out, vocabulary was also a reliable predictor, although the contribution of span was only marginal. (If allocation policy variables were entered after ability measures, their contribution was weakened somewhat, explaining $10 \%$ of the variance in performance; in this case, effort toward reprocessing did not contribute, but situation model processing remained a strong predictor; $p<.01.)^{3}$

\section{CONCLUSIONS}

Our data are generally consistent with earlier literature on rereading that has shown a decrease in resource allocation to lexical and textbase processing with reprocessing (e.g., Millis et al., 1998; Raney, 2003). Younger readers allocated relatively less time to lexical processing in rereading, and for narrative texts, less time to the textbase as well. Older readers showed similar effects, but to a lesser extent, suggesting that relatively more of their analysis of lexical features and textbase content occurred in reprocessing (whereas younger readers completed relatively more of their analysis on the first pass). The evidence for greater rereading benefits for younger adults, relative to older adults, suggests that (1) the lexical and (at least, for narratives) the textbase representations of older readers are not as thoroughly elaborated (or as resistant to decay) as those of younger readers and that (2) older readers are sensitive to the fact that these representations are impoverished. The flip side of this is that older readers take differential advantage of reprocessing to repair incomplete computations.

The exception to this principle was in the allocation to textbase processing in expository passages describing scientific research. In this case, older readers seemed to neglect textbase processing in rereading. Although this might be interpreted as a differential rereading benefit demonstrating especial efficiency in textbase construction among older readers, this explanation seems implausible in light of a literature showing that effective propositional analysis requires more time among older readers (e.g., Hartley et al., 1994; Stine \& Hindman, 1994; Stine \& Wingfield, 1990). Rather, this may reflect an example of withdrawing resources from where they are not likely to be effective (e.g., Metcalfe, 2002).

Age differences were arguably most pronounced in situation model processing. For both expository and narrative texts, the older adults allocated relatively more attention than the young to the situation model when first encountering the text, thus supporting the idea that older readers are more immediately attuned to the more holistic structures of discourse (Adams et al., 1997; Radvansky, 1999).

Finally, these data suggest that there are individual differences in the self-regulation of language input and that these differences have implications for comprehension. Independent of ability measures, those showing better comprehension performance allocated more time to situation model processing and allocated differentially more time to reprocessing. Even though some aspects of language processing may be driven by "dumb processes" (Gerrig \& McKoon, 2001), our data suggest that language understanding is also self-regulatory and that older readers may regulate their attention differently from the young to maintain high levels of comprehension.

\section{REFERENCES}

Aaronson, D., \& Scarborough, H. S. (1977). Performance theories for sentence coding: Some quantitative models. Journal of Verbal Learning \& Verbal Behavior, 16, 277-303.

Ackerman, P. L., \& Rolfhus, E. L. (1999). The locus of adult intelligence: Knowledge, abilities, and nonability traits. Psychology \& Aging, 14, 314-330.

Adams, C., Smith, M. C., Nyquist, L., \& Perlmutter, M. (1997). Adult age-group differences in recall for the literal and interpretive meanings of narrative text. Journal of Gerontology: Psychological Sciences, 52B, P187-P195.

Amlund, J. T., Kardash, C. A., \& Kulhavy, R. W. (1986). Repetitive reading and recall of expository text. Reading Research Quarterly, 21, 49-58.

BARSALOU, L. W. (1999). Perceptual symbol systems. Behavioral \& Brain Sciences, 22, 577-660.

BRITTON, B. K. (1994). Understanding expository text: Building mental structures to induce insights. In M. A. Gernsbacher (Ed.), Handbook of psycholinguistics (pp. 641-674). New York: Academic Press.

Carstensen, L. L., \& Turk-Charles, S. (1994). The salience of emotion across the adult life-span. Psychology \& Aging, 9, 259-264.

Chinen, A. B. (1992). Once upon the midlife. New York: Putnam.

Chute, D. L., \& Westall, R. F. (1997). PowerLaboratory. Devon, PA: MacLaboratory, Inc.

CrAiK, F. I. M., \& ANDERSON, N. D. (1999). Applying cognitive research to problems of aging. In D. Gopher \& A. Koriat (Eds.), Attention and performance XVII: Cognitive regulation of performance. Interaction of theory and application (pp. 584-615). Cambridge, MA: MIT Press.

Craik, F. I. M., \& Jennings, J. M. (1992). Human memory. In F. I. M. Craik \& T. A. Salthouse (Eds.), The handbook of aging and cognition (pp. 51-110). Hillsdale, NJ: Erlbaum. 
Craik, F. I. M., \& Simon, E. (1980). Age differences in memory: The role of attention and depth processing. In L. W. Poon, J. L. Fozard, L. S. Cermak, D. L. Arenberg, \& L. W. Thompson (Eds.), New directions in memory and aging: Proceedings of the George A. Talland Memorial Conference (pp. 95-112). Hillsdale, NJ: Erlbaum.

Dixon, R. A., Simon, E. W., NowaK, C. A., \& Hultsch, D. F. (1982). Text recall in adulthood as a function of level of information, input modality, and delay interval. Journal of Gerontology, 37, 358-364.

Dunlosky, J., \& ConNOR, L. T. (1997). Age differences in the allocation of study time account for age differences in memory performance. Memory \& Cognition, 25, 691-700.

FRANCIS, N. W., \& KUČERA, H. (1982). Frequency analysis of English usage: Lexicon and grammar. Boston: Houghton-Mifflin.

GERNSBACHER, M. A. (1990). Language comprehension as structure building. Hillsdale, NJ: Erlbaum.

Gerrig, R. J., \& McKoon, G. (2001). Memory processes and experiential continuity. Psychological Science, 12, 81-85.

Graesser, A. C. (1981). Prose comprehension beyond the word. New York: Springer-Verlag.

Graesser, A. C., Hoffman, N. L., \& Clark, L. F. (1980). Structural components of reading time. Journal of Verbal Learning \& Verbal Behavior, 19, 135-180.

HABERLANDT, K. F. (1984). Components of sentence and word reading times. In D. E. Kieras \& M. A. Just (Eds.), New methods in reading comprehension research (pp. 219-251). Hillsdale, NJ: Erlbaum.

Haberlandt, K. F., Graesser, A. C., Schneider, N. J., \& Kiely, J. (1986). Effects of task and new arguments on word reading times. Journal of Memory \& Language, 25, 314-322.

HAEngGi, D., \& PerfetTI, C. A. (1992). Individual differences in reprocessing text. Journal of Educational Psychology, 84, 182-192.

HaRris, J. L., Rogers, W. A., \& QuALLS, C. D. (1998). Written language comprehension in younger and older adults. Journal of Speech, Language, \& Hearing Research, 41, 603-617.

Hartley, J. T., Stojack, C. C., Mushaney, T. J., Annon, T. A. K., \& LeE, D. W. (1994). Reading speed and prose memory in older and younger adults. Psychology \& Aging, 9, 216-223.

HeMingway, E. (1966). The short stories of Ernest Hemingway. New York: Scribner. (Original work published 1925)

Isaacowitz, D. M., Charles, S. T., \& Carstensen, L. L. (2000). Emotion and cognition. In F. I. M. Craik \& T. A. Salthouse (Eds.), The handbook of aging and cognition (pp. 593-631). Mahwah, NJ: Erlbaum.

Johnson, R. E. (2003). Aging and the remembering of text. Developmental Review, 23, 261-346.

Just, M. A., \& CARpenter, P. (1980). A theory of reading: From eye fixations to comprehension. Psychological Review, 87, 329-354.

Just, M. A., \& CARPENTER, P. (1992). A capacity theory of comprehension: Individual differences in working memory. Psychological Review, 99, 122-149.

KINTSCH, W. (1994). Text comprehension, memory, and learning. American Psychologist, 49, 294-303.

KINTSCH, W. (1998). Comprehension: A paradigm for cognition. New York: Cambridge University Press.

Kintsch, W., \& VAN DiJK, T. A. (1978). Toward a model of text comprehension and production. Psychological Review, 85, 363-394.

Levy, B. A., Campsall, J., Browne, J., CoOper, D., Waterhouse, C., \& WiLson, C. (1995). Reading fluency: Episodic integration across texts. Journal of Experimental Psychology: Learning, Memory, \& Cognition, 21, 1169-1185.

LeVy, B. A., Di Persio, R., \& Hollingshead, A. (1992). Fluent rereading: Repetition, automaticity, and discrepancy. Journal of Experimental Psychology: Learning, Memory, \& Cognition, 18, 957-971.

LeVy, B. A., \& KirSNer, K. (1989). Reprocessing text: Indirect measures of word and message level processes. Journal of Experimental Psychology: Learning, Memory, \& Cognition, 15, 407-417.

Levy, B. A., Newell, S., SNyder, J., \& Timmins, K. (1986). Processing changes across reading encounters. Journal of Experimental Psychology: Learning, Memory, \& Cognition, 12, 467-478.

LiGHT, L. L., \& CAPPS, J. L. (1986). Comprehension of pronouns in younger and older adults. Developmental Psychology, 22, 580-585.

LitTLE, D. M. (2001). Age and attentional constraints on the encoding and recall of spoken discourse. Unpublished doctoral dissertation, Brandeis University.

LORCH, R. F., \& MYERS, J. L. (1990). Regression analyses of repeated measures data in cognitive research. Journal of Experimental Psychology: Learning, Memory, \& Cognition, 16, 149-157.

MCGINNIS, D., \& ZELINSKI, E. M. (2000). Understanding unfamiliar words: The influence of processing resources, vocabulary knowledge, and age. Psychology \& Aging, 15, 335-350.

Metcalfe, J. (2002). Is study time allocated selectively to a region of proximal learning? Journal of Experimental Psychology: General, 131, 349-363.

MEYER, B. J. F., \& Poon, L. W. (2001). Effects of structure strategy training and signaling on recall of text. Journal of Educational Psychology, 93, 141-159.

Miles, J. R., \& Stine-Morrow, E. A. L. (in press). Adult age differences in self-regulated learning in reading sentences. Psychology \& Aging.

Miller, L. M. S., \& Stine-Morrow, E. A. L. (1998). Aging and the effects of knowledge on on-line reading strategies. Journal of Gerontology: Psychological Sciences, 53B, P223-P233.

Millis, K. K., KING, A., \& KIM, H. J. (2000). Updating situation models from descriptive texts: A test of the situational operator model. Discourse Processes, 30, 201-236.

Millis, K. K., Simon, S., \& tenBroek, N. S. (1998). Resource allocation during the rereading of scientific texts. Memory \& Cognition, 26, 232-246.

MorRow, D. G., Greenspan, S. L., \& Bower, G. H. (1987). Accessibility and situation models in narrative comprehension. Journal of Memory \& Language, 26, 165-187.

Morrow, D. G., Stine-Morrow, E. A. L., Leirer, V. O., Andrassy, J. M., \& KAHN, J. (1997). The role of reader age and focus of attention in creating situation models from narratives. Journal of Gerontology: Psychological Sciences, 52B, P73-P80.

RadVAnsky, G. A. (1999). Aging, memory, and comprehension. Current Directions in Psychological Science, 8, 49-53.

Radvansky, G. A., ZwaAn, R. A., Curiel, J. M., \& Copeland, D. E. (2001). Situation models and aging. Psychology \& Aging, 16, 145-160.

RANEY, G. E. (2003). A context-dependent representation model for explaining text repetition effects. Psychonomic Bulletin \& Review, 10, $\underline{15-28 .}$

RANEY, G. E., Therriault, D. J., \& MinKofF, S. R. B. (2000). Repetition effects from paraphrased text: Evidence for an integrated representation model of text representation. Discourse Processes, 29, 61-81.

Rawson, K. A., Dunlosky, J., \& Thiede, K. W. (2000). The rereading effect: Metacomprehension accuracy improves across reading trials. Memory \& Cognition, 28, 1004-1010.

SALTHOuSE, T. A. (1988). Resource-reduction interpretations of cognitive aging. Developmental Review, 8, 1-35.

Salthouse, T. A., Kausler, D., \& Saults, J. S. (1988). Investigation of student status, background variables, and feasibility of standard tasks in cognitive aging research. Psychology \& Aging, 3, 29-37.

Sharkey, N. E., \& SharkeY, A. J. C. (1987). What is the point of integration? The loci of knowledge-based facilitation in sentence processing. Journal of Memory \& Language, 26, 255-276.

Smiler, A. P., GaGne, D. D., \& Stine-Morrow, E. A. L. (2003). Aging, memory load, and resource allocation during reading. Psychology \& Aging, 18, 203-209.

Speranza, F., Daneman, M., \& Schneider, B. A. (2000). How aging affects the reading of words in noisy backgrounds. Psychology \& Aging, 15, 253-258.

STINE, E. A. L. (1990). On-line processing of written text by younger and older adults. Psychology \& Aging, 5, 68-78.

Stine, E. A. L., Cheung, H., \& Henderson, D. T. (1995). Adult age differences in the on-line processing of new concepts in discourse. Aging \& Cognition, 2, 1-18.

Stine, E. A. L., \& HiNDMAN, J. (1994). Age differences in reading time allocation for propositionally dense sentences. Aging \& Cognition, $\mathbf{1}$, 2-16.

Stine, E. A. L., Soederberg, L. M., \& Morrow, D. G. (1996). Language and discourse processing through adulthood. In F. Blanchard- 
Fields \& T. M. Hess (Eds.), Perspectives on cognitive change in adulthood and aging (pp. 255-290). New York: McGraw-Hill.

STine, E. A. L., \& WingField, A. (1990). How much do working memory deficits contribute to age differences in discourse memory? $\underline{E u-}$ ropean Journal of Cognitive Psychology, 2, 289-304.

Stine, E. A. L., \& WingField, A. (1994). Older adults can inhibit highprobability competitors in speech recognition. Aging \& Cognition, 1 , 152-157.

Stine-Morrow, E. A. L., Loveless, M. K., \& Soederberg, L. M. (1996). Resource allocation in on-line reading by younger and older adults. Psychology \& Aging, 11, 475-486.

Stine-Morrow, E. A. L., Milinder, L., Pullara, O., \& Herman, B. (2001). Patterns of resource allocation are reliable among younger and older readers. Psychology \& Aging, 16, 69-84.

Stine-Morrow, E. A. L., Miller, L. M. S., \& Leno, R. (2001). Patterns of on-line resource allocation to narrative text by younger and older readers. Aging, Neuropsychology, \& Cognition, 8, 36-53.

Stine-Morrow, E. A. L., Morrow, D. G., \& Leno, R. (2002). Aging and the representation of spatial situations in narrative understanding. Journal of Gerontology: Psychological Sciences, 57B, P91-P97.

TAUB, H. A. (1979). Comprehension and memory of prose materials by young and old adults. Experimental Aging Research, 5, 3-13.

VAN DEN BRoEK, P. (1994). Comprehension and memory of narrative texts: Inferences and coherence. In M. A. Gernsbacher (Ed.), Handbook of psycholinguistics (pp. 539-588). San Diego: Academic Press.

ZABRUCKY, K., \& MoORE, D. (1994). Contributions of working memory and evaluation and regulation of understanding to adults' recall of texts. Journal of Gerontology: Psychological Sciences, 49, P201-P212.

ZelinsKi, E. M., \& GILEWSKI, M. J. (1988). Memory for prose and aging: A meta-analysis. In M. L. Howe \& C. Brainerd (Eds.), Cognitive development in adulthood: Progress in cognitive development research (pp. 133-158). New York: Springer-Verlag.

Zwaan, R. A., Magliano, J. P., \& Graesser, A. C. (1995). Dimensions of situation model construction in narrative comprehension. Journal of Experimental Psychology: Learning, Memory, \& Cognition, 21, 386-397.

ZWAAN, R. A., \& RADVANSKY, G. A. (1998). Situation models in language comprehension and memory. Psychological Bulletin, 123, 162-185.

\section{NOTES}

1. University students (12-17 years of formal education, $M=12.49$ years, mode $=12$ ) were compared with healthy elders who were generally well educated but diverse in this regard (8-20 years of formal education, $M=15.89$ years, mode $=16$ ), raising the issue that our younger and older samples were not otherwise comparable. Analyses were conducted in such a way as to include only older adults with $12-18$ years of education $(n=36)$. This did not change the pattern of the results or the significance levels of the inferential statistics reported, so we will report analyses from the full sample. One concern might be that even within that range, older adults were more highly educated than the young, since most had completed a college education. However, the younger sample was on a trajectory for finishing college, and it would be hard to argue that any advantage for the older adults would be due to the residual effects of $2-3$ years of education 50 years earlier. Education has many direct beneficial effects on cognition, as well as effects on lifestyle that promote cognitive growth, but a sample with 1 or 2 years of college (most of whom will complete bachelor's degrees, and some of whom will complete master's degrees) is probably not different from a sample of older college graduates from the same community. Another concern might be whether student status itself (i.e., current participation in formal education), which also differed between the groups, might contribute to age differences. To the extent that this has been investigated in cognitive aging, it does not appear that it makes a difference (Salthouse, Kausler, \& Saults, 1988).

2. Our original intent had been to model reading times in terms of a broader representation of situation model variables (Zwaan \& Radvansky, 1998), and so narrative segments were also coded for emotionality of sectors (on the basis of student ratings) to test the notion that older readers are relatively more attentive to emotion-laden text segments (Carstensen \& Turk-Charles, 1994), as well as temporal and character shifts (Zwaan et al., 1995). In our preliminary analyses, emotionality was never positively related to median reading time, although occasionally a negative relationship was shown, suggesting a relatively fast reading of more emotional segments. We assume this was due to the fact that segments rated as more emotional also tended to be semantically simpler. In addition, in our narratives, temporal and character shifts tended to co-occur with spatial shifts, which were more reliably related to median reading times. Thus, these three variables were not included in the individual regressions.

3. If years of formal education was entered first into the equation, the picture did not substantively change, with both resource allocation and ability still contributing to performance. In this model, $30.5 \%$ of the variance was accounted for. Education explained $6.6 \%$ of the variance in performance (std. $\beta=.278, p<.01$ ). Allocation variables explained $14 \%$ of the variance, with situation model allocation carrying the effect (std. $\beta=.426, p<.001$ ) and the contribution from rereading slope dropping below significance ( $\operatorname{std} . \beta=.142, p=.172$ ). Not surprisingly, the effects of individual differences in ability were weakened somewhat with the effects of education controlled, accounting for $6.8 \%$ of the variance, with working memory span (std. $\beta=.224, p<.05$ ) and vocabulary (std. $\beta=.258, p<.05$ ) both positive predictors of performance. With the effects of these variables partialled out, age contributed marginally to the equation (adj. $R^{2}=.031$, std. $\left.\beta=-.207, p=.061\right)$. 
APPENDIX A

Descriptive Statistics for Passage Characteristics

\begin{tabular}{lccrr}
\hline \multicolumn{1}{c}{ Characteristic } & Minimum & Maximum & $M$ & $S D$ \\
\hline & Expository Passages (Experiment 1$)$ & & \\
Syllables & 6.00 & 34.00 & 16.58 & 6.22 \\
Average log frequency & 1.41 & 3.33 & 2.62 & 0.33 \\
New concepts & 0.00 & 4.00 & 1.18 & 0.97 \\
Propositions & 1.00 & 9.00 & 4.88 & 1.87 \\
Imagery & 1.62 & 3.77 & 2.73 & 0.56 \\
Importance & 1.72 & 3.70 & 2.40 & 0.41 \\
Serial position & 1.00 & 78.00 & 35.77 & 21.01 \\
& & & \\
Syllables & Folk Tales (Experiment & & \\
Average log frequency & 2.00 & 23.00 & 13.467 & 4.85 \\
New concepts & 1.78 & 3.23 & 2.74 & 0.29 \\
Propositions & 0.00 & 4.00 & 0.89 & 0.88 \\
Imagery & 1.00 & 10.00 & 4.73 & 1.73 \\
Spatial discontinuity & 1.40 & 3.24 & 2.18 & 0.45 \\
Serial position & 0.00 & 1.00 & 0.25 & 0.43 \\
& 1.00 & 85.00 & 37.67 & 22.77 \\
Syllables & Hemingway Stories (Experiment & & \\
Average log frequency & 1.00 & 28.00 & & \\
New concepts & 1.00 & 3.46 & 12.467 & 5.02 \\
Propositions & 0.00 & 5.00 & 2.88 & 0.33 \\
Imagery & 1.00 & 12.00 & 0.76 & 0.98 \\
Spatial discontinuity & 1.44 & 3.94 & 4.55 & 1.99 \\
Serial position & 0.00 & 1.00 & 2.76 & 0.54 \\
\hline & 1.00 & 76.00 & 0.16 & 0.37 \\
& & & 37.52 & 21.48 \\
\hline
\end{tabular}

APPENDIX B

Cell Means for Allocation Parameters

(Mean Coefficients from Individual Regressions)

\begin{tabular}{|c|c|c|c|c|c|c|c|c|}
\hline \multirow[b]{3}{*}{ Parameter } & \multicolumn{4}{|c|}{ Younger Readers } & \multicolumn{4}{|c|}{ Older Readers } \\
\hline & \multicolumn{2}{|c|}{ First Reading } & \multicolumn{2}{|c|}{ Second Reading } & \multicolumn{2}{|c|}{ First Reading } & \multicolumn{2}{|c|}{ Second Reading } \\
\hline & $M$ & $S E$ & $M$ & $S E$ & $M$ & $S E$ & $M$ & $S E$ \\
\hline \multicolumn{9}{|l|}{ Expository } \\
\hline Syllables & 140 & 11 & 86 & 9 & 144 & 9 & 127 & 10 \\
\hline Log word frequency & -112 & 73 & -52 & 65 & -263 & 64 & -275 & 82 \\
\hline New concepts & 88 & 37 & 65 & 36 & 199 & 40 & 31 & 34 \\
\hline Propositions & 69 & 22 & 89 & 17 & 40 & 22 & 56 & 26 \\
\hline Imagery & 68 & 54 & 162 & 65 & 66 & 58 & 113 & 55 \\
\hline Importance & -334 & 61 & -438 & 104 & -609 & 84 & -554 & 71 \\
\hline Serial position & -3.1 & 1.6 & -6.1 & 1.8 & -4.1 & 2.2 & -5.3 & 1.7 \\
\hline \multicolumn{9}{|l|}{ Folk tales } \\
\hline Syllables & 97 & 8 & 69 & 7 & 79 & 6 & 75 & 7 \\
\hline Log word frequency & -375 & 46 & -308 & 78 & -221 & 38 & -234 & 68 \\
\hline New concepts & 205 & 25 & 69 & 21 & 232 & 46 & 141 & 60 \\
\hline Propositions & 133 & 14 & 62 & 12 & 112 & 13 & 83 & 20 \\
\hline Imagery & 258 & 40 & 139 & 42 & 230 & 29 & 116 & 42 \\
\hline Spatial shift & 198 & 41 & 247 & 59 & 33 & 40 & 76 & 46 \\
\hline Serial position & -5.5 & 1.0 & -0.4 & 1.2 & -2.6 & 1.1 & 1.2 & 1.1 \\
\hline \multicolumn{9}{|l|}{ Hemingway stories } \\
\hline Syllables & 183 & 12 & 137 & 10 & 170 & 10 & 140 & 10 \\
\hline Log word frequency & -170 & 45 & -76 & 56 & -305 & 45 & -149 & 60 \\
\hline New concepts & 260 & 33 & 225 & 29 & 345 & 51 & 264 & 31 \\
\hline Propositions & 52 & 18 & 47 & 16 & 65 & 16 & 84 & 18 \\
\hline Imagery & -44 & 41 & 135 & 45 & 179 & 51 & 138 & 57 \\
\hline Spatial shift & 122 & 65 & 97 & 61 & 413 & 49 & 342 & 67 \\
\hline Serial position & 0.3 & 1.3 & 2.5 & 1.3 & 3.2 & 1.0 & 5.5 & 1.1 \\
\hline
\end{tabular}

(Manuscript received November 19, 2002;

revision accepted for publication January 9, 2004.) 